\title{
Association of Lance Adams syndrome and Post- Traumatic Stress Disorder in the context of cerebellar injury: a case report
}

Delphine Terrier ( $\nabla$ delphine.terrier8@gmail.com )

Hopital d'Instruction des Armees Laveran https://orcid.org/0000-0003-2146-2274

\section{Frédéric Paul}

Hopital d'Instruction des Armées Laveran

Jonas Endale Geda

Barrow Neurological Institute

\section{Anthony Faivre}

Hopital d'Instruction des Armees Sainte Anne: HIA Sainte Anne

\section{Bernard François Michel}

Hopital d'Instruction des Armées Laveran

\section{Case report}

Keywords: Post-traumatic stress disorder, cerebelar injury, Lance Adams syndrome

Posted Date: December 21st, 2020

DOl: https://doi.org/10.21203/rs.3.rs-125753/v1

License: (9) This work is licensed under a Creative Commons Attribution 4.0 International License. Read Full License 


\section{ASSOCIATION OF LANCE ADAMS SYNDROME AND POST-TRAUMATIC STRESS DISORDER IN THE CONTEXT OF CEREBELAR INJURY:}

\section{A CASE REPORT}

Terrier Delphine, MD; Paul Frédéric, PH D; Geda Jonas Endale, MD; Faivre Anthony, MD; Michel Bernard François, MD

Terrier Delphine, Laveran Teaching Military Hospital, Department of psychiatry, Marseille, FRANCE Paul Frédéric, Laveran Teaching Military Hospital, Department of psychiatry, Marseille, FRANCE Geda Jonas Endale, Barrow Neurological Institute, Department of Neurology, Phoenix, ARIZONA, USA

Faivre Anthony, Sainte Anne Teaching Military Hospital, Department of neurology, Toulon, FRANCE Michel Bernard François, Laveran Teaching Military Hospital, Department of psychiatry, Marseille, FRANCE

Search Terms: Cerebellum, Myoclonus, Post Traumatic Stress Disorder, Cerebellar Cognitive and Affective Syndrome, Lance Adams Syndrome

Submission Type: Case Report

Title Character count: 103

Number of Tables: 0

Number of Figures: 1

Word count of Abstract: 221

Word Count of Paper: 998

\section{Corresponding Author:}

Terrier Delphine

Laveran Teaching Military Hospital, Department of psychiatry,

34 boulevard Laveran,

13013, Marseille, FRANCE

Phone: +336.34.64.93.97 - +334.91.61.79.17 - FAX: +334.91.61.71.71

delphine.terrier8@gmail.com 
Ethics approval and consent to participate: not applicable

Consent for publication: the patient gave his consent for informations about himself to be published.

Availability of data and materials: not applicable

\section{Competing interests:}

Terrier Delphine: Reports no competing of interest

Paul Frédéric: Reports no competing of interest

GEDA Jonas Endale: Reports no competing of interest

Faivre Anthony: Reports no competing of interest

Michel Bernard François: Reports no competing of interest

Funding: not applicable

Authors' informations and contributions:

\begin{tabular}{|c|c|c|c|}
\hline Name & Location & Role & Contribution \\
\hline Terrier Delphine, MD & $\begin{array}{l}\text { Laveran Teaching Military } \\
\text { Hospital, Marseille }\end{array}$ & Author & $\begin{array}{l}\text { Drafting and research for } \\
\text { intellectual content }\end{array}$ \\
\hline Paul Frédéric, PH D & $\begin{array}{l}\text { Laveran Teaching Military } \\
\text { Hospital, Marseille }\end{array}$ & Author & $\begin{array}{l}\text { Drafting and revision for } \\
\text { intellectual content }\end{array}$ \\
\hline Geda Jonas Endale, MD & $\begin{array}{l}\text { Barrow Neurological Institute, } \\
\text { Phoenix }\end{array}$ & Author & $\begin{array}{l}\text { Drafting and revision of } \\
\text { manuscript }\end{array}$ \\
\hline Faivre Anthnoy, MD & $\begin{array}{l}\text { Sainte Anne Teaching Military } \\
\text { Hospital, Toulon }\end{array}$ & Author & $\begin{array}{l}\text { Clinical and paraclinical } \\
\text { expertise of the patient }\end{array}$ \\
\hline $\begin{array}{l}\text { Michel Bernard François, } \\
\text { MD }\end{array}$ & $\begin{array}{l}\text { Laveran Teaching Military } \\
\text { Hospital, Marseille }\end{array}$ & Author & $\begin{array}{l}\text { Drafting and research for } \\
\text { intellectual content }\end{array}$ \\
\hline
\end{tabular}

Acknowledgements: not applicable 


\begin{abstract}
Background: only 150 cases of LANCE-ADAMS syndrome (LAS) has been reported. In this paper, we present the case of a subject suffering from LANCE-ADAMS syndrome and post-traumatic stress disorder (PTSD) in the context of cerebellar anoxic lesions confirmed by Magnetic Resonance Imaging (MRI) and Positron Emission Tomography (PET-FDG).

Case presentation: LANCE-ADAMS syndrome is a myoclonic post-anoxic syndrome and the involvement of cerebellum in pathogenesis of cortical myoclonic syndromes has been hypothesized. Prominent motor signs of our patient were adiadococinaesia in the upper limbs and ataxic dysarthria without alteration of linguistic functions. Right cerebellar hemisphere, dominant for speech production, connects with lower precentral gyrus in the left frontal lobe, and contributes to language production. This network also appears to be engaged in cognitive functions, such as verbal working memory. The main cognitive problems of our patient were difficulties in verbal episodic memory tasks and dysexecutive syndrome. Recent work has shown important functional interactions between the cerebellum and the hippocampal formation. The predominant psychiatric feature of the patient was post-traumatic stress disorder, which appeared before motor signs and persisted after improvement. It could be related to a decrease of functional connectivity between the posterior cerebellum and prefrontal regions.
\end{abstract}

Conclusions: These findings suggest the potential role of the cerebellar region in the psychopathology of PTSD. Our clinical case suggests the potential link between post-traumatic stress disorder and the affective component of the entity known as the "Cerebellar Cognitive and Affective Syndrome » (CCAS) described in 1998 by Schmahmann \& Sherman.

\title{
INTRODUCTION
}

The classical role of cerebellum in the coordination of sensory-motor functions is well established. The involvement of the cerebellum in cognition is a relatively recent discovery (WAGNER \& LUO, 2019), but it is now well recognized. However, it is only in very recent literature that it is suggested that the cerebellum may play a critical role in emotion regulation processes and psychosocial interactions (GUELL et al., 2018). Post-hypoxic myoclonus may develop on awakening from coma within 48 hours of cardiorespiratory arrest. There is also a chronic form of post-anoxic myoclonic syndrome that was first described in 1963 by LANCE and ADAMS in four cases. The involvement of the cerebellum in post- 
anoxic myoclonic syndromes has been established in some cases such as that of Waddel (WADDELL $e t$ al.,2017). We report the observation of a patient suffering from an association of LAS and PTSD, where clinical manifestations involved both neurological and psychiatrical findings, underpinned by cerebellar anoxia insult supported by clinical, MRI of the brain and FDG-PET findings.

\section{CASE PRESENTATION}

On June 15, 2011, Mister H..., a 49 years old policeman, without any medical history, intervened in emergency on a burning house. After several minutes of effort, despite the heavy smoke, the policeman was able to evacuate the elderly inhabitant of the house. However, the policeman lost consciousness for several minutes after leaving the house. One month later, the policeman reported sleep disturbances, with intrusive traumatic recollection of the event (nocturnal visual and auditory intrusive recollections with frequent sensations of suffocation), subsequently he was diagnosed with PTSD. In January 2012, language disorders appeared, first with intermittent pseudo-stuttering, then progressed to dysarthria. the unusual presence of language impairment in PTSD, initially led to consideration of a conversive disorder. But $4 \%$ of conversion disorders are misdiagnosed as organic pathologies (STONE et al., 2005). In January 2017, the patient was evaluated in the psychiatric department of Laveran Army Training Hospital. The diagnosis of PTSD was confirmed, but neurological examination revealed both myoclonic and cerebellar syndromes. Peri-oral focal myoclonus and diffuse myoclonus of the upper limbs were present. The patient exhibited a cerebellar dysarthria with adiadococinaesia and upper limbs dysmetria (kinetic tremor). Neuropsychological examination revealed essentially an impairment of episodic verbal memory, with a deficit of total and delayed recall. There was a slight dysexecutive syndrome with perseverations; language assessment was normal (fluency and denomination). The electroencephalogram (EEG) showed generalized spikes and poly-spots favored by intermittent light stimulation, associated with diffuse myoclonus (photo-myoclonic). MRI of the brain revealed a cerebellar hemispheric atrophy. On PET-FDG, we could see a severe cerebellar hypo-metabolism, affecting cerebellar hemispheres and vermis with bilateral frontoparietal hypo-metabolism (Figure). Extensive blood workup and cerebrospinal fluid analysis were normal. Based on clinical findings and typical EEG pattern, the diagnosis of LAS with cerebellar involvement, was made. A treatment with Lévétiracétam was initiated and a follow-up consultation at 3 months showed clinical improvement with reduction of myoclonus and partial correction of dysarthria. A neurological check-up at 18 months showed that the neurological disorders almost disappeared, with normalization of EEG. From psychiatric perspective, PTSD persisted. 


\section{DISCUSSION}

MRI has made it possible to revisit the functional anatomy of the cerebellum, by defining fissures, and lobules. Path tracing, using diffusion tensor imaging (DTI), shows that the proportion of cerebellar connections with the frontal regions is greater than with motor areas. Moreover, connections cerebellum-cortex are topographically organized, with the anterior cerebellum (lobules I-IV) receiving the majority of inputs from the sensory motor zone, whereas the posterior cerebellum is more connected to associative and prefrontal regions of the cortex (Schmahmann et al., 2000). LAS is a myoclonic postanoxic syndrome and the involvement of cerebellum in pathogenesis of cortical myoclonic syndromes has been hypothesized. The combination of alterations in inhibitory neurotransmission and the presence of cerebellar pathology are important elements in the pathogenesis of cortical myoclonus (Ganos et al., 2014). Prominent motor signs of our patient were adiadococinaesia in the upper limbs and dysarthria without alteration of linguistic functions. These pathological alterations in phonation and articulation were designated as ataxic dysarthria and result of an involvement of articulatory movements of the tongue and orofacial muscles. Right cerebellar hemisphere, dominant for speech production, connects with lower precentral gyrus in the left frontal lobe, and contributes to language production. Besides motor control, this network also appears to be engaged in cognitive functions, such as verbal working memory (Bodranghien et al., 2016). The main cognitive problems of our patient were difficulties in verbal episodic memory tasks and, and some degree of dysexecutive syndrome supported by, severe cerebellar and bilateral fronto-parietal hypo-metabolism on PET-FDG. The cerebellum is associated with verbal memory and executive tasks and recent work has shown important functional interactions between the cerebellum and the hippocampal formation (Bernard et al., 2013). The predominant psychiatric feature of the patient was PTSD, which appeared before motor signs. The PTSD persisted whereas the motor signs i.e. myoclonus improved with Lévétiracétam treatment. Rabellino (Rabellino et al., 2018), observed a decreased functional connectivity between the posterior cerebellum and prefrontal regions in PTSD subjects. Our observation is consistent with the observation made by Rabellino. These findings suggest the potential role of the cerebellar region in the psychopathology of PTSD. Finally, our clinical case suggests the potential link between PTSD and the affective component of the entity known as the «Cerebellar Cognitive and Affective Syndrome » (CCAS) (Schmahmann \& Sherman, 1998), in which implicates the posterior vermis and the fastigial nucleus.

\section{PATIENT PERSPECTIVES}

PTSD being diagnosed was recognized as a service-related injury. However, language impairment, previously considered a conversive disorders, was not taken into account. The identification of the cerebellar impairment and the diagnosis of LAS finally allowed this occupational disease to be 
considered and allowed the patient to enter a path of repair. This recognition of the occupational disease brought relief to the patient. Moreover, thanks to the drug, the neurological disorders almost disappeared.

\section{Abbreviations:}

LAS: LANCE-ADAMS syndrome

PTSD: post-traumatic stress disorder

MRI: Magnetic Resonance Imaging

PET-FDG: Positron Emission Tomography

CCAS: Cerebellar Cognitive and Affective Syndrome

EEG: electroencephalogram

DTI: diffusion tensor imaging

Figure. TEP TDM. Severe bilateral hemispheric cerebellar and at a least degree bilateral frontoparietal hypo-metabolism. April 42018. 


\section{REFERENCES}

1. Wagner M.J., Luo L. (2019). Neocortex-Cerebellum Circuits for Cognitive Processing. Trends Neurosci. Nov 28.

2. Guell X., Gabrieli J.D.E., Schmahmann J.D. (2018) Triple representation of language, working memory, social and emotion processing in the cerebellum: convergent evidence from task and seedbased resting-state fMRI analyses in a single large cohort. Neuroimage 172: 437-449.

3. Waddell A., Dirweesh A., Ordonez F., et al. Lance-Adams syndrome associated with cerebellar pathology. Journal of community hospital internal medicine perspectives; 2017; 7: 182-184.

4. Schmahmann JD, Doyon J., Toga AW, et al. MRI atlas of the human. cerebellum. Academic Press; San Diego, 2000; 167 pp.

5. Ganos C., Kassavetis P., Erro R., et al. The role of the cerebellum in the pathogenesis of cortical myoclonus. Mov Disord. 2014; 29: 437-443.

6. Bodranghien F., Bastian A., Casali C., et al. Consensus Paper: Revisiting the Symptoms and Signs of Cerebellar Syndrome. Cerebellum. 2016; 15: 369-391.

7. Bernard JA, Peltier SJ, Wiggins JL, et al. Disrupted cortico-cerebellar connectivity in older adults. Neuroimage; 2013; 83: 103-119.

8. Rabellino D., Densmore M., Theberge J., et al. The cerebellum after trauma: resting-state functional connectivity of the cerebellum in posttraumatic stress disorder and it dissociative subtype. Hum brain Mapp; 2018; 39: 3354-3374.

9. Schmahmann JD, Sherman JC. The cerebellar cognitive affective syndrome. Brain; 1998; 121: 561-579. 


\section{Figures}

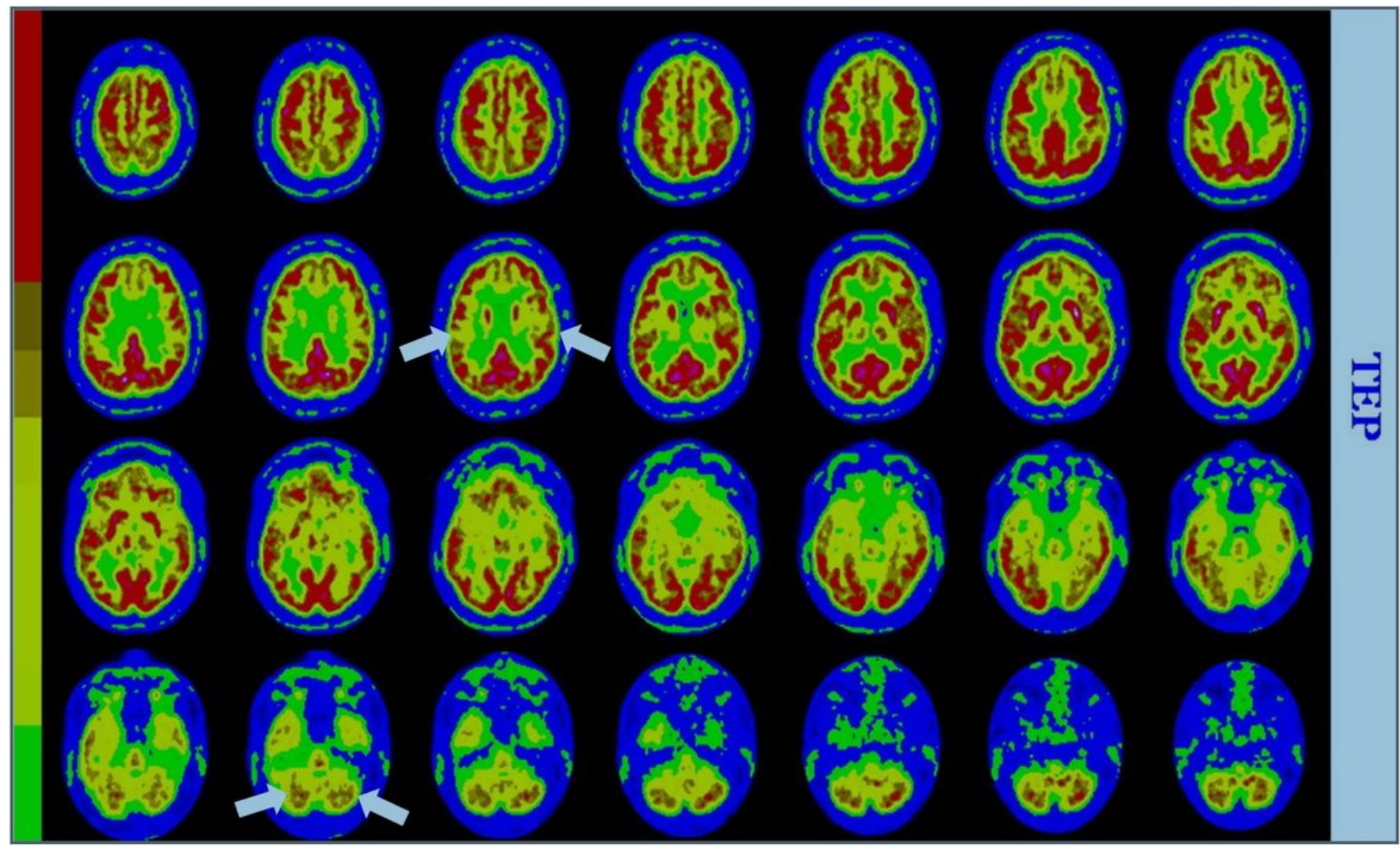

Figure 1

TEP TDM. Severe bilateral hemispheric cerebellar and at a least degree bilateral frontoparietal hypometabolism. April 42018. 